\title{
Establishing 293T suspension cultrue for lentiviral vector production in a stirred bioreactor
}

\author{
Qulai Tang ${ }^{1}$, Lixing $\mathrm{Gu}^{2}$, Han $\mathrm{Wu}^{2}$, Fan $\mathrm{Li}^{2}$, Haichuan $\mathrm{Zhu}^{2}$, Chaojiang $\mathrm{Gu}^{2}$, Shangkun \\ Zhang $^{2}$, Jinjue Liang ${ }^{2}$, Wei Qi ${ }^{1}$, Yong Zhou ${ }^{2}$, and Tongcun Zhang ${ }^{1}$ \\ ${ }^{1}$ Tianjin University of Science and Technology \\ ${ }^{2}$ Wuhan University of Science and Technology
}

November 10, 2020

\begin{abstract}
293T suspensions cells were first cultured in a big bubble-stirred bioreactors for large-scale lentivirus vectors (LV) production in the study. Direct domesticated approaches were utilized for 293 suspensions cells. We validated of the ability to LV package and drew a growth curve in shake flask. The results show $293 \mathrm{~T}$ suspension culture was successful, and also retained the capacity for LV production. After facile optimization of the viral package and cryopreservation conditions, 293T suspension cells were inoculated in a 5.5 L bioreactor. Packaged CAR-CD30 lentivirus yield was close to that from the original shake flask culture. Cultivation for 4 days in the bioreactor enabled production of $1.5 \pm 0.3 \times 107 \mathrm{TU} / \mathrm{mL}$ coarse $\mathrm{LV}$ and the lentiviral infection efficiency was $48.6 \pm 2.8 \%$ in $\mathrm{T}$ Cells. The process has merits of low cost as well as more effective, and expected to be highly competitive compared to other bioreactors.
\end{abstract}

Establishing 293T suspension cultrue for lentiviral vector production in a stirred bioreactor

Qulai Tang ${ }^{1}$ \#, Lixing $\mathbf{G u}^{2}$ \#, Han $\mathrm{Wu}^{2}$, Fan $\mathrm{Li}^{2}$, Haichuan $\mathrm{Zhu}^{2}$, Chaojiang $\mathrm{Gu}^{2}$, Shangkun Zhang ${ }^{2}$, Jinjue Liang ${ }^{2}$, Wei $\mathrm{Qi}^{1}$, Yong Zhou ${ }^{2}$, Tongcun Zhang ${ }^{1,2}$

Key Laboratory of Industrial Fermentation Microbiology of the Ministry of Education, Tianjin University of Science and Technology, Tianjin 300457, China.

College of Life Science and Health, Wuhan University of Science and Technology, Wuhan, Hubei 430065, China;

*Correspondence: Dr Tongcun Zhang, College of Biotechnology, Tianjin University of Science and Technology, Tianjin, China.Email:tony@tust.edu.cn; Dr Yong Zhou, College of Life Science and Health, Wuhan University of Science and Technology, Wuhan, Hubei, China. Email:zy110cn@126.com.

\# Shared first authors have contributed equally to this article.

Keywords Acclimation; 293T suspensions cells; Lentivirus vectors; Stirred bioreactors; CAR-T cell therapy.

Abstract 293T suspensions cells were first cultured in a big bubble-stirred bioreactors for large-scale lentivirus vectors (LV) production in the study. Direct domesticated approaches were utilized for 293 suspensions cells. We validated of the ability to LV package and drew a growth curve in shake flask. The results show 293T suspension culture was successful, and also retained the capacity for LV production. After facile optimization of the viral package and cryopreservation conditions, 293T suspension cells were inoculated in a $5.5 \mathrm{~L}$ bioreactor. Packaged CAR-CD30 lentivirus yield was close to that from the original shake flask culture. Cultivation for 4 days in the bioreactor enabled production of $1.5 \pm 0.3 \times 10^{7} \mathrm{TU} / \mathrm{mL}$ coarse $\mathrm{LV}$ and the 
lentiviral infection efficiency was $48.6 \pm 2.8 \%$ in $\mathrm{T}$ Cells. The process has merits of low cost as well as more effective, and expected to be highly competitive compared to other bioreactors.

\section{Introduction}

Human immunodeficiency virus-derived lentiviral vectors (HIV-1) are widely used as gene delivery tools in cell therapies and genetic disease treatments. Presently, cell therapy drugs for blood cancers, represented by chimeric antigen receptor (CAR-T) therapy, are being used in clinical practice (Aiuti et al., 2013; CavazzanaCalvo et al., 2000; Mukherjee \& Thrasher, 2013). Since CAR-T cell therapy is necessarily individualized and precise, the quality and therapeutic effectiveness of CAR-T cells depends on sound production processes. At its core, the production of CAR-T cells is the production of lentivirus, and a scale-up of this process is vital (McCarron, Donnelley, McIntyre, \& Parsons, 2016). Currently, large-scale production and purification of high-titer lentivirus is a bottleneck for mainstream CAR-T manufacturers.

Traditional 293T cell culture utilizes monolayer, or adherent, serum culture (Marin et al., 2016). However, the serum composition is complex and batch differences affect cells. Also, trypsin, used to process adherent culture, causes cell fragility, thus leading to partial membrane rupture and increasing the risk of contamination by animal ingredients (Otsuji et al., 2014); therefore, increasing trypsin amounts reduce the virus titer. Most of vaccines or LV in stationary culture systems are scaled up using cell factories and roller bottles which are labour intensive and susceptible to contamination (Bora, Yousuf, Dhar, \& Singh, 2018). While research showed that the virus yield in adherent culture was higher than that in suspension culture, the inherent growth limitation of adherent culture surface area caused the total virus yield in the adherent culture to be lower than that in the suspension culture (Merten, Hebben, \& Bovolenta, 2016). Given equal culture volumes, lentivirus packaging titer of 293T cells in suspension was nearly 3.5 times higher than that of adherent 293T cells (Smith \& Shioda, 2009). Compare that to serum-free culture, which is clear and stable, can avoid adverse cell interactions, maintains excellent repeatability, and simplifies the upstream process and large-scale cell culture for high-density growth (Sheu et al., 2015). Ongoing development of serum-free medium cultivation is the current trend of mammalian cell culture technology (Pham et al., 2003), e.g., MDCK (Nakamura et al., 2019), BHK21 (Nikolay, Castilho, Reichl, \& Genzel, 2018), CHO (J. Wu et al., 2016).

Stirred bioreactors with the advantage of repeated sterilization operations and low cost become as an attractive approach for practical purposes in both microbial and cell culture applications (Taiani et al., 2010). The bioreactor have been widely used in the biopharmaceutical industry recently (Kuystermans, Avesh, \& Al-Rubeai, 2016). It is noteworthy that most of 293T cell employed in the large scale production of virus are cultivated on suspended micro-carriers in the bioreactors (Guy, McCloskey, Lye, Mitrophanous, \& Mukhopadhyay, 2013). But the cost of lentiviral packaging is high, and the process of cell sampling observation, culture and large-scale production is complex (S. C. Wu, Huang, \& Liu, 2002). In literature, the reports are few on $239 \mathrm{~T}$ cell suspension culture in the bioreactors without micro-carriers. The ventilation system of stirred bioreactors can be classified as large bullae systems or microbubbles systems. Comparatively, physical rupturing of cells caused by excessive mechanical agitation or aeration in bioreactors is more susceptible to occur in bullae systems (Chuan et al., 2006).

Thus, the development of $239 \mathrm{~T}$ cell suspension culture with bullae systems in a stirred bioreactors without micro-carriers is a major challenge. We try to domesticate $293 \mathrm{~T}$ adherent cells during short duration into suspension cells, and maximize large-scale production of LV in a 15-L 3-impeller agitating bioreactor.

\section{Materials and Methods}

\section{Materials}

We purchased the human renal epithelial cell line (293T) from American Type Tissue Collection (CRL3216,ATCC, Manassas, VA); DMEM, FBS, $0.25 \%$ trypsin-EDTA, and glutamic acid from Gibco, (ThermoFisher Scientific, USA); 293 CD05 medium and OPM-CHO PFF06 medium from Shanghai OPM Biotechnology Co. Ltd. (Shanghai, China), are serum-free, inorganic salts, amino acids and vitamins; SMM293-TII from Sino Biological Inc. (Beijing, China) is a serum-free medium designed for the cultivation of a mam- 
malian cell type; Polybrene from MilliporeSigma (St. Louis, MO, USA); and Escherichia coli DH5 $\alpha$ from TIANGEN Biotech Co., Ltd. (Beijing, China). The expression plasmid (PTK-GFP), polyethylenimine (PEI), and packaged plasmid (pMDLg-pRRE, pRSV-REV, and pMD2.G) were provided by Wuhan Bio-raid Biotechnology Co., Ltd. (Wuhan, China).

\section{F medium andcryopreservation solutions}

Our serum-free medium, comprised of equal parts 293 CD05 medium and SMM293-TII, was named F medium. Cryopreservation solutions were $10 \%$ DMSO plus either $90 \%$ fetal bovine serum (FBS), human serum albumin (HSA) or F medium, and respectively named FBS cryopreservation solutionI, HSA cryopreservation solutionII, and F medium cryopreservation solution IV, as well as an additional $25 \%$ HSA and $65 \% \mathrm{~F}$ medium cryopreservation solution III. Besides FBS, all materials were of un-animal origin in this study.

\section{Cell adaption}

Adherent $293 \mathrm{~T}$ cells were passaged after 3 days, using $0.25 \%$ trypsin-EDTA to detach cells from dishes. The cell survival rate was more than $90 \%$. Those cells, with a passage density of $4.0 \times 10^{5} \mathrm{cells} / \mathrm{mL}$, were replaced that medium with $\mathrm{F}$ medium for cell adaption. The cells were inoculated at a density of $4.0 \times 10^{5} \mathrm{cells} / \mathrm{mL}$ into a $20 \mathrm{~mL} / 125 \mathrm{~mL}$ triangulation flask. The cells were cultivated at 37 and $130 \mathrm{rpm}$ on a shaking incubator (sk-r1807-e,SCTLOGEX, America) with $5 \% \mathrm{CO}_{2}$.

\section{Preparation of suspension cell passages and growth curve determination}

Stable fourth-generation cells were removed and cultured for 8 days with cell densities of $1.0 \times 10^{5}$ cells $/ \mathrm{mL}$ (group A), $2.0 \times 10^{5}$ cells $/ \mathrm{mL}$ (group B), and $4.0 \times 10^{5}$ cells $/ \mathrm{mL}$ (group C) for $24 \mathrm{~h}$ to determine cell density, total number of cells, and cell viability. We used a hemocytometer (717805, Blaubrand, Germany) to record cell density. Cell viability was determined using trypan blue staining (Hauck et al., 2016).

\section{LV packaging verification}

Four Escherichia coli DH5 $\alpha$ cultures transfected with green fluorescent protein (GFP)-expressing plasmids and packaged plasmids were incubated overnight while oscillating. Then the plasmids were extracted with a large plasmid extraction kit (QIAGEN, Germany). Using PEI-mediated transfection, the 4 plasmid packaging systems were used to transfect suspension cells. The 293T suspension cells were cultured in shaking flasks and mixed with the 4 plasmids without exchange medium on the second day.

We used fluorescence microscopy to observe the fluorescence intensity at $24 \mathrm{~h}$. After $72 \mathrm{~h}$, we used high speed centrifugation before taking $100 \mu \mathrm{L}$ of the suspension cell supernatant and using the HIV p24 Antigen Rapid Test Cassette (Botelong Immunotechnologies Co.,Ltd, Suzhou, China) to determine the packaging effect. To begin transfection, we inoculated 6 -well plates with $293 \mathrm{~T}$ cells at a density of $5.0 \times 10^{5}$ cells $/ \mathrm{mL}$, and followed that with 0-112 $\mu \mathrm{L}$ supernatant and $4 \mathrm{~g} / \mathrm{mL}$ polybrene. Three days later, the $293 \mathrm{~T}$ transfection efficiency was detected by flow cytometer. Wells with fewer than 10-25\% GFP-positive cells were chosen to calculate the transduction titer $(\mathrm{TU} / \mathrm{mL}$ ) using the following formula: (total transduced cell number $\times$ proportion of positive cells)/ (virus volume in $\mu \mathrm{L}$ ).

\section{LV packaging conditions optimization}

The packaging effects of GFP-LV in serum-free F medium, both with and without $6 \mathrm{mM}$ L-glutamine, were compared at 48 and $72 \mathrm{~h}$ post transfection. We also compared the effects of supplementation on virus packaging by examining 4 groups (blank [control] group, $6 \mathrm{mM}$ L-glutamine group, 5\% CHO PFF06 group, and $6 \mathrm{mM} \mathrm{L-glutamine}+5 \%$ CHO PFF06 group) at $24 \mathrm{~h}$ post transfection.

\section{Cryopreservation solution optimization}

We first placed $1 \mathrm{~mL} 293 \mathrm{~T}$ suspension cells (density $1.0 \times 10^{7}$ cells $/ \mathrm{mL}$ ) in each of 12 sterilized Eppendorf tubes, centrifuged them, and discarded the supernatant. Then we resuspended the cell pellets with $1 \mathrm{~mL}$ 
of either cryopreservation solutionI, cryopreservation solutionII, cryopreservation solution III, or cryopreservation solution IV, each in 3 tubes. The tubes were held at -80 overnight and then transferred to liquid nitrogen for preservation. After resuscitation, the effects of these different cryopreservation solutions on cell morphology and cell growth was observed by microscope and the best cryopreservation solution was selected for packaging batches of CAR-CD30 LV to examine LV packaging.

\section{Bioreactor cultivation}

We used a 15-L 3-impeller agitating bioreactor (Z4AEZ0015M, Applikon Biotechnology, Netherlands) with a working volume of $5.5 \mathrm{~L}$ containing $0.1 \%$ (v/v) non-ionic surfactant Pluronic F-68 (Sigma-Aldrich, America), a constant $130 \mathrm{rpm}$ stirring speed, and 50\% dissolved oxygen level. Air was applied to the surface while air and $\mathrm{CO}_{2}$ bubbled up from below. When the dissolved oxygen fell below a certain value, oxygen was pumped in from the bottom. To test for aseptic conditions and reactor airtightness, 48 hours before beginning the experiment, we pumped a portion of fresh medium into the reactor. Once the experiment began, a constant 37 , and $7.1 \mathrm{pH}$ were maintained. Both fermentation and transfection conditions were followed by a flask shaking system to pack CAR-CD30 LV in the bioreactor. When cell density reached $1.5 \times 10^{6}$ cells $/ \mathrm{mL}$, the plasmid complex was added at $10 \%$ of the working volume. After $24 \mathrm{~h}$ of transfection, $5 \%$ of the working volume of the supplemented medium was added. The culture supernatants were harvested at 48-72 $\mathrm{h}$ posttransfection by ultracentrifugation according to previous studies and then allowed to infect primary $\mathrm{T}$ cells with a multiplicity of infection (MOI) of 20 . The T-cells were acquired form volunteers who participated in this study agreed and signed Informed Consent, and transfected according to previously described methods (Hsiao et al., 2020). Three days after transfection, the cells were used for flow cytometer to evaluate the transfection efficiency.

\section{Statistics}

The data are representative of three independent experiments. GraphPad 6 and Flowjo V10 were used for statistical analysis. The data are presented as the mean+-standard deviation. The comparison between groups was done by a two-way analysis of variance test followed by Tukey's test. Values less than 0.05 were considered to be statistically significant and $\mathrm{p}$ values $<0.05$ or $<0.01$ were indicated by $*$ or ${ }^{* *}$, respectively.

\section{Results}

\section{Adherent cell cultivation in serum-free medium}

Figure 1a shows that after 12 subcultures, adaption cell density expanded from $4.0 \times 10^{5}$ cells $/ \mathrm{mL}$ to $1.7+-$ $0.4-4.7+-0.5 \times 10^{6}$ cells $/ \mathrm{mL}$ over 3 days, while cell viability of more than $95 \%$ was maintained. The second domesticated generation of 293T suspension cells had a relatively high rate of cell aggregation (Fig. 1b). After two passage, the cells were spherical and uniformly sized, with good dispersion and brightness. Suspension 293T cells in F medium mostly remained single, with aggregates of up to 5 cells in Figure 1b.

After we observed with successive generations, 293T suspension cells had adapted to serum-free F medium, without a depolymerizer or a microcarrier; and aggregation amount. The cell density and viability had reached acceptable levels.

\section{T suspension cell growth curve}

To determine optimal growth conditions for 293T suspension cells, the growth parameters of 3 different incubated cell concentrations were examined: $1.0 \times 10^{5}$ cells $/ \mathrm{mL}$ (Group A), 2.0x10 cells $/ \mathrm{mL}$ (group B) and $4.0 \times 10^{5}$ cells $/ \mathrm{mL}$ (group C). Initially, all groups experienced increasing viable cell density, but group C began decreasing on day 6 and groups $\mathrm{A}$ and $\mathrm{B}$ began decreasing on day 7 (Fig. 2a). The results of the percentage of cell viability were consistent and group C's high inoculation density had relatively little influence on cell viability in the early stages of culture (Fig. 2b). Figure 2c shows that the total cell density in $125 \mathrm{~mL}$ flasks reached $1.3+-0.5 \times 10^{7}$ cells $/ \mathrm{mL}$ at $7 \mathrm{~d}$. After that, the cell density and activity of the culture gradually decreased. 
These experimental results demonstrated that $20 \mathrm{~mL} \mathrm{~F}$ medium meets basic nutritional requirements of 293T suspension cells cultured at Group C's high inoculation density for 6 days.

\section{Suspension cell virus packaging abilities}

GFP, used to detect the viral packaging ability of adapted $293 \mathrm{~T}$ suspension cells, fluoresced strongly in those cells (Fig. 3a) within 24 hours. The supernatant produced by suspension cell LV packaging was used to infect $293 \mathrm{~T}$ adherent cells, and the culture medium was collected after 72 hours. After centrifugation and filtration, a protein card test verified positive results (Fig. 3b). The positive rate of GFP expression in infected cells increased in step with the increasing volume of transfected virus and the virus titer $\left(1.2 \times 10^{7}\right.$ $\mathrm{TU} / \mathrm{mL}$ ) was calculated as the positive rate of GFP cells with about $16.8+-1.3 \%$ conversion (Fig. 3c and 3d). These results indicate that when $293 \mathrm{~T}$ adherent cells were adapted into suspension cells, they maintained both GFP expression and virus replication ability.

\section{Optimization of cultivation conditions for LV packaging}

During suspension cell cultivation, both added L-glutamine and differing incubation times influenced LV packaging efficiency. First, the average virus titer for $\mathrm{F}$ medium without L-glutamine was $36 \%(\mathrm{P}<0.01)$ higher than that with L-glutamine (Fig. 4a). After $48 \mathrm{~h}$ of incubation, the virus titer was about $47 \%$ (P < 0.01 ) higher than that at 72 hours. Therefore, the suspension cell culture process does not need additional L-glutamine and the virus is best harvested at $48 \mathrm{~h}$.

However, compared with the blank control, virus titer increased $45 \%(\mathrm{P}<0.01)$ after the addition of $\mathrm{CHO}$ PFF06, increased $18 \%$ after the addition of L-glutamine and CHO PFF06, but decreased $4 \%$ after the addition of L-glutamine (Fig. 4b). Therefore, the more appropriate culture conditions for 293T suspension cells are: F medium for culture, $5 \%$ CHO PFF06 added $24 \mathrm{~h}$ post transfection, followed by harvest at $48 \mathrm{~h}$. Under those conditions, the GFP LV package titer was $3.3+-0.2 \times 10^{7} \mathrm{TU} / \mathrm{mL}$.

\section{Cryopreservation solution optimization}

Adherent $293 \mathrm{~T}$ cells acclimated well to serum-free culture suspension, indicating that the serum-free formula should be used for cryopreservation. When we tested our 4 possible cryopreservation solutions to find the optimum solution for suspended 293T culture; we found that, compared with solutionsI, II, and III, P1 generation cells in solution IV aggregated the least after thawing and had better stability for 3 consecutive generations (Fig. 5a). After 3 days of cultivation, the density of solution IV cells reached 3.0+$0.4 \times 10^{6}$ cells $/ \mathrm{mL}$ with cell viability of $98.0+-2.0 \%$, the highest values for all 4 solutions (Fig. $5 \mathrm{~b}$ ). Therefore, adding $10 \%$ DMSO directly to the culture medium for cryopreservation not only reduced protein involvement, and reduced process cost, but also aided cryopreservation.

The CAR-CD30 plasmid was used to verify whether resuscitated 293T cells could pack the CAR-CD30 LV. Figure $5 \mathrm{c}$ shows that after the $293 \mathrm{~T}$ cells were resuscitated, the cells still had an average $1.7+-0.2 \times 10^{7}$ $\mathrm{TU} / \mathrm{mL}$ CAR-CD30 virus packaging capability in shake-flasks.

\section{Bioreactor cultivation and LV packaging}

The adapted $293 \mathrm{~T}$ cell line also proved to be suitable for cultivation in the bioreactor. After 2 days of fermentation at a cell density of $3.8+-0.4 \times 10^{5}$ cells $/ \mathrm{mL}(130 \mathrm{rpm}, 50 \% \mathrm{OD}, \mathrm{pH} 7.1$, and 37 ), cell viability was greater than $90 \%$ and growth had steadily increased, indicating that suspension cells can grow stably in a bioreactor (Fig. 6a). The titer of CAR-CD30 virus, detected by flow cytometer (Fig. 6b) at $72 \mathrm{~h}$ post transfection of adherent $293 \mathrm{~T}$ cells, was about $1.5+-0.3 \times 10^{7} \mathrm{TU} / \mathrm{mL}$. These results showed that cultured suspension cells could not only grow stably in the bioreactor but could also pack LV at a titer similar to that of flask transfection. T Cells were infected with the crude virus $(\mathrm{MOI}=20)$ and the infection efficiency was $48+-0.3 \%((\mathrm{P}<0.01))$ after $72 \mathrm{~h}$ post-transduction (Fig. 6c, 6d).

\section{Discussion}

Cell adaptation to suspension growth was not every time as straightforward and successful as previously 
described (Gallo-Ramirez, Nikolay, Genzel, \& Reichl, 2015). A stepwise reduction of percentage of FBS was performed to adapt serum-free culture condition, and it usually takes at least 1-2 months (Lee, Park, \& Seo, 2020; Rourou, Ben Zakkour, \& Kallel, 2019). More recent studies have indicated that during adaptation, certain cell lines may also change their expression of surface receptors, which then affects production purposes (de Los Milagros Bassani Molinas, Beer, Hesse, Wirth, \& Wagner, 2014). 293 CD05 medium, OPM-CHO PFF06 medium and SMM293-TIIare free of any animal-derived components and designed for 293T cell lines. Here, we demonstrated the feasibility of the commercial serum-free medium 293 CD05, OPM-CHO PFF06 and SMM293-TII for 293T cells to LV manufacture. In this study, we successfully adapted 293T adherent cells into 293T suspension cells about a week. Those suspension cells had a stable proliferation, and no need for genetically modification (Humbert et al., 2016), microcarriers (Guy et al., 2013) and antiaggregate solvents (Rourou et al., 2019) to stay uniformly dispersed suspension. After $3 \mathrm{~d}$ of cultivation, cell density had reached at least 3.8 times. Cells can keep their susceptibility and permissiveness to allow efficient virus replication (Frey et al., 2010). After multiple passages and cryopreservation recovery, the suspension cells had a stable proliferation and maintained their ability to package virus. Therefore, we have successfully completed the critical process steps to enable a large-scale, clinical LV production process in a relatively short period.

Additionally, the optimized components of suspension cell culture medium, culture conditions, and virus harvest time can improve LV titer (Hsu \& Uluda $\breve{g}$, 2012; Karolewski, Watson, Parente, \& Wolfe, 2003). This was consistent with the experimental results that the virus titer increased $36 \%(\mathrm{P}<0.01)$ after without L-glutamine addition, 47\% $(\mathrm{P}<0.01)$ after $48 \mathrm{~h}$ of incubation, $45 \%(\mathrm{P}<0.01)$ after the addition of $\mathrm{CHO}$ PFF06. Under those conditions, the GFP LV package titer was about $3.3 \pm 0.2 \times 10^{7} \mathrm{TU} / \mathrm{mL}$.

Suspension cultures are amenable for process automation as well as for easy regulation and control of optimized conditions, resulting in being the current choice for most large-scale biomanufacturing applications in bioreactor (Warnock \& Al-Rubeai, 2006). Today, a variety of stirred-tank bioreactors with well characterized hydrodynamic properties are available for cell culture (Costariol et al., 2019). However, the bioreactor demonstrated a deficiency in shear forces and oxygen transfer rates (Gallo-Ramírez et al., 2015). In this study, we have shown that the 15-L and 3-impeller agitating bioreactor can be used to culture human 293T cells at high-density and package LV which infected T cells. Suspension cells in a 5.5-L working volume of the bioreactor can be produced about $1.5 \pm 0.3 \times 10^{7} \mathrm{TU} / \mathrm{ml}$ CAR-CD30 virus stock solution. The production period was just about 4 days.

Compared with other studies, our study not only made the procedure efficient but also has done complete process flow from acclimation to cryopreservation, shake flask to bioreactor as well as the utility of this crude virus, which laid the foundation for further scale-up and eventual industrial application. This study also has significance as a reference for the development of similar 293T-derived produces in the future. However, it was only a preliminary study and there are several optimum proposal to carry out for the complete technological process, such as cultivation, transfection and purification process (Tinch, Szczur, Swaney, Reeves, \& Witting, 2019).

\section{Author Disclosure Statement}

All authors have contributed to the creation of this manuscript and have read and approved it as submitted. We declare there are no conflicts of interest.

\section{Acknowledgements}

We thank Han Wu, Fan Li, Haichuan Zhu, Chaojiang Gu, Shangkun Zhang, Jinjue Liang and Wei Qi for their excellent technical assistance. In particular, we appreciate Professor Yong Zhou's expert assistance and Professor Tongcun Zhang for providing the platform for all this research. This study was supported by grants from the National Key R \& D Program of China (2017YFD0400304), the Innovative Research Team of Tianjin Municipal Education Commission (TD13-5015) and Wuhan Science and Technology Plan Project (2019030703011533). 


\section{References}

Bora, M., Yousuf, R. W., Dhar, P., \& Singh, R. P. (2018). An overview of process intensification and thermo stabilization for upscaling of Peste des petits ruminants vaccines in view of global control and eradication. Virusdisease, 29 (3), 285-296. doi:10.1007/s13337-018-0455-3

Chuan, K. H., Lim, S. F., Martin, L., Yun, C. Y., Loh, S. O., Lasne, F., \& Song, Z. (2006). Caspase activation, sialidase release and changes in sialylation pattern of recombinant human erythropoietin produced by $\mathrm{CHO}$ cells in batch and fed-batch cultures. Cytotechnology, 51 (2), 67-79. doi:10.1007/s10616-006-9016-5

Costariol, E., Rotondi, M., Amini, A., Hewitt, C. J., Nienow, A. W., Heathman, T. R. J., . . . Rafiq, Q. A. (2019). Establishing the scalable manufacture of primary human T-cells in an automated stirred-tank bioreactor. Biotechnol Bioeng, 116 (10), 2488-2502. doi:10.1002/bit.27088

de Los Milagros Bassani Molinas, M., Beer, C., Hesse, F., Wirth, M., \& Wagner, R. (2014). Optimizing the transient transfection process of HEK-293 suspension cells for protein production by nucleotide ratio monitoring. Cytotechnology, 66 (3), 493-514. doi:10.1007/s10616-013-9601-3

Frey, S., Vesikari, T., Szymczakiewicz-Multanowska, A., Lattanzi, M., Izu, A., Groth, N., \& Holmes, S. (2010). Clinical efficacy of cell culture-derived and egg-derived inactivated subunit influenza vaccines in healthy adults. Clin Infect Dis, 51 (9), 997-1004. doi:10.1086/656578

Gallo-Ramirez, L. E., Nikolay, A., Genzel, Y., \& Reichl, U. (2015). Bioreactor concepts for cell culture-based viral vaccine production.Expert Rev Vaccines, 14 (9), 1181-1195. doi:10.1586/14760584.2015.1067144

Guy, H. M., McCloskey, L., Lye, G. J., Mitrophanous, K. A., \& Mukhopadhyay, T. K. (2013). Characterization of lentiviral vector production using microwell suspension cultures of HEK293T-derived producer cells. Hum Gene Ther Methods, 24 (2), 125-139. doi:10.1089/hgtb.2012.200

Hauck, V., Hugli, P., Meli, M. L., Rostaher, A., Fischer, N., Hofmann-Lehmann, R., \& Favrot, C. (2016). Increased numbers of FoxP3-expressing CD4+ CD25+ regulatory $\mathrm{T}$ cells in peripheral blood from dogs with atopic dermatitis and its correlation with disease severity. Vet Dermatol, 27 (1), 26 -e29. doi:10.1111/vde.12279

Hsiao, F., Frouard, J., Gramatica, A., Xie, G., Telwatte, S., Lee, G. Q., . . . Roan, N. R. (2020). Tissue memory CD4+ T cells expressing IL-7 receptor-alpha (CD127) preferentially support latent HIV-1 infection.PLoS Pathog, 16 (4), e1008450. doi:10.1371/journal.ppat.1008450

Hsu, C. Y., \& Uludă̆, H. (2012). A simple and rapid nonviral approach to efficiently transfect primary tissue-derived cells using polyethylenimine. Nat Protoc, 7 (5), 935-945. doi:10.1038/nprot.2012.038

Humbert, O., Gisch, D. W., Wohlfahrt, M. E., Adams, A. B., Greenberg, P. D., Schmitt, T. M., . . . Kiem, H. P. (2016). Development of Third-generation Cocal Envelope Producer Cell Lines for Robust Lentiviral Gene Transfer into Hematopoietic Stem Cells and T-cells.Mol Ther, 24 (7), 1237-1246. doi:10.1038/mt.2016.70

Karolewski, B. A., Watson, D. J., Parente, M. K., \& Wolfe, J. H. (2003). Comparison of transfection conditions for a lentivirus vector produced in large volumes. Hum Gene Ther, 14 (14), 1287-1296. doi:10.1089/104303403322319372

Kuystermans, D., Avesh, M., \& Al-Rubeai, M. (2016). Online flow cytometry for monitoring apoptosis in mammalian cell cultures as an application for process analytical technology. Cytotechnology, 68 (3), 399-408. doi:10.1007/s10616-014-9791-3

Lee, D. K., Park, J., \& Seo, D. W. (2020). Suspension culture of Vero cells for the production of adenovirus type 5. Clin Exp Vaccine Res, 9 (1), 48-55. doi:10.7774/cevr.2020.9.1.48 
Merten, O. W., Hebben, M., \& Bovolenta, C. (2016). Production of lentiviral vectors. Mol Ther Methods Clin Dev, 3 , 16017. doi:10.1038/mtm.2016.17

Nakamura, K., Harada, Y., Takahashi, H., Trusheim, H., Bernhard, R., Hamamoto, I., . . . Yamamoto, N. (2019). Systematic evaluation of suspension MDCK cells, adherent MDCK cells, and LLC-MK2 cells for preparing influenza vaccine seed virus. Vaccine, 37 (43), 6526-6534. doi:10.1016/j.vaccine.2019.08.064

Nikolay, A., Castilho, L. R., Reichl, U., \& Genzel, Y. (2018). Propagation of Brazilian Zika virus strains in static and suspension cultures using Vero and BHK cells. Vaccine, 36 (22), 3140-3145. doi:10.1016/j.vaccine.2017.03.018

Pham, P. L., Perret, S., Doan, H. C., Cass, B., St-Laurent, G., Kamen, A., \& Durocher, Y. (2003). Largescale transient transfection of serum-free suspension-growing HEK293 EBNA1 cells: peptone additives improve cell growth and transfection efficiency. Biotechnol Bioeng, 84 (3), 332-342. doi:10.1002/bit.10774

Rourou, S., Ben Zakkour, M., \& Kallel, H. (2019). Adaptation of Vero cells to suspension growth for rabies virus production in different serum free media. Vaccine, 37 (47), 6987-6995. doi:10.1016/j.vaccine.2019.05.092

Sheu, J., Beltzer, J., Fury, B., Wilczek, K., Tobin, S., Falconer, D., . . . Bauer, G. (2015). Large-scale production of lentiviral vector in a closed system hollow fiber bioreactor. Mol Ther Methods Clin Dev, 2 , 15020. doi:10.1038/mtm.2015.20

Smith, S. L., \& Shioda, T. (2009). Advantages of COS-1 monkey kidney epithelial cells as packaging host for small-volume production of high-quality recombinant lentiviruses. J Virol Methods, 157 (1), 47-54. doi:10.1016/j.jviromet.2008.12.002

Taiani, J. T., Krawetz, R. J., Zur Nieden, N. I., Elizabeth Wu, Y., Kallos, M. S., Matyas, J. R., \& Rancourt, D. E. (2010). Reduced differentiation efficiency of murine embryonic stem cells in stirred suspension bioreactors. Stem Cells Dev, 19 (7), 989-998. doi:10.1089/scd.2009.0297

Tinch, S., Szczur, K., Swaney, W., Reeves, L., \& Witting, S. R. (2019). A Scalable Lentiviral Vector Production and Purification Method Using Mustang Q Chromatography and Tangential Flow Filtration. Methods Mol Biol, 1937, 135-153. doi:10.1007/978-1-4939-9065-8_8

Wu, J., Han, D., Wei, M., Zheng, G., Jiao, D., Xi, W., . . . Wen, W. (2016). [Domestication of suspension $\mathrm{CHO}$ cells and its application in the expression of anti-PSMA antibody]. Xi Bao Yu Fen Zi Mian Yi Xue Za Zhi, 32 (1), 1-4.

Wu, S. C., Huang, G. Y., \& Liu, J. H. (2002). Production of retrovirus and adenovirus vectors for gene therapy: a comparative study using microcarrier and stationary cell culture. Biotechnol Prog, 18 (3), 617622. doi:10.1021/bp020026p 
Fig.1
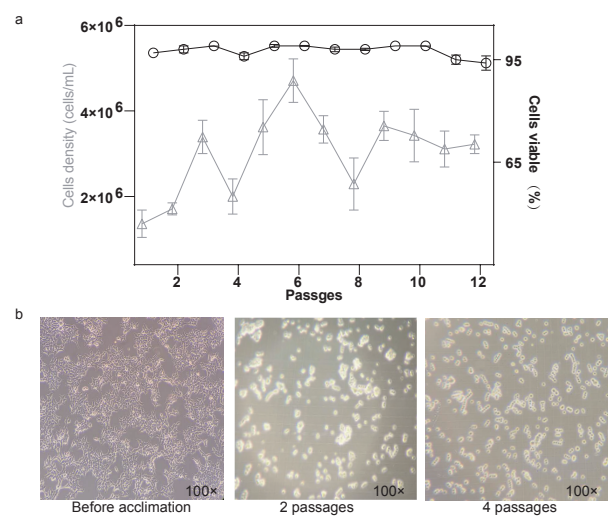

Figure 1. 293T suspension cells grown in shake flasks in $\mathrm{F}$ medium during cell adaptation.

(a) The percentage of cell growth and viability. (b) Unstained cells were observed with an inverted light microscope at $100 \times$ magnification.

Fig. 2

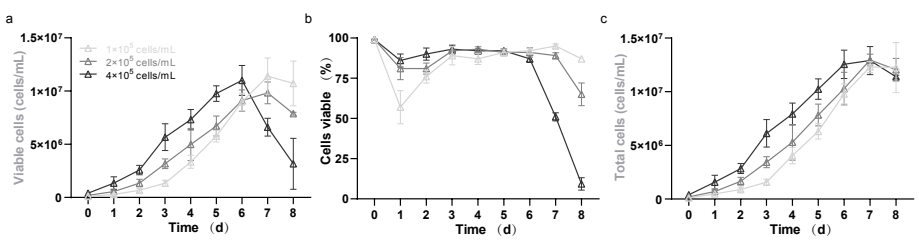

Figure 2. Growth results over 8 d of adapted suspension 293T cells at different inoculation densities. (a) Live cell growth curve; (b) Cell viability percentages; (c) Total cells growth curve. Data are means (SD) of 3 experiments. 
Fig.3

a

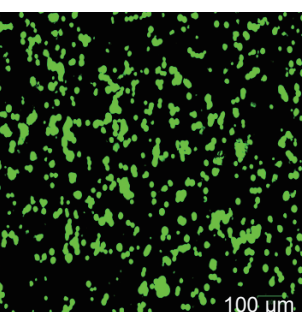

c

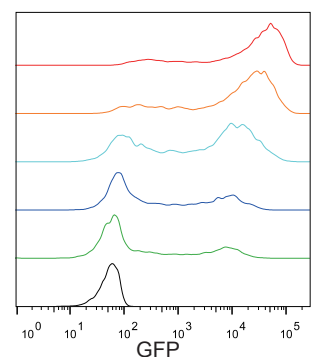

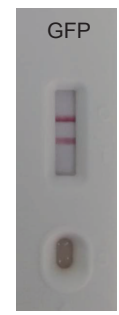

d

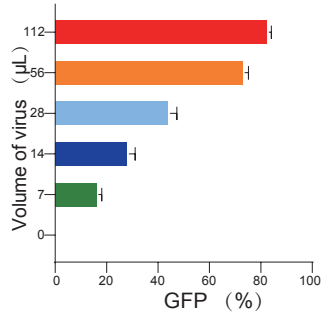

Figure 3. Verification of virus packaging capability of 293T suspension cells. (a) Observation of GFP intensity in 293T suspension cells after infection using $100 \mu \mathrm{m}$ for green field microscopy. (b) $100 \mu \mathrm{L}$ cell supernatant was collected, treated at $72 \mathrm{~h}$ post-transfection, and tested using an HIV p24 Antigen Rapid Test Cassette. The test shows positive results (2 horizontal lines)

(c, d) Inoculated GFP+ 293T cells with 6 increasing amounts $(0-112 \mu \mathrm{L})$ of the supernatant were detected using flow cytometer.
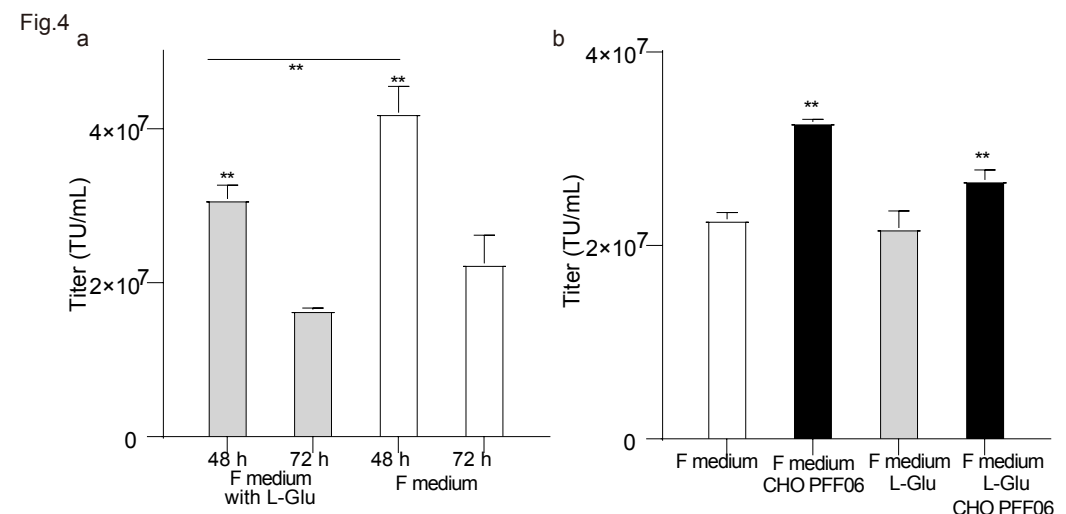

Figure 4. The effects of cultivating conditions on viral packaging. (a) 293T suspension cells incubated in $\mathrm{F}$ medium (white bars) and $\mathrm{F}$ medium supplemented with $6 \mathrm{mM}$ L-glutamine (gray bars) for 3 passages and packaged virus and harvested at 48 and $72 \mathrm{~h}$. (b) After determining that additional L-glutamine was not needed and $48 \mathrm{~h}$ was the optimal harvest time, 4 media were supplemented at $24 \mathrm{~h}$ after transfection to find the best relationship between nutritional media and virus production. Those 4 media were $\mathrm{F}$ medium (control), $\mathrm{F}$ medium with $5 \% \mathrm{CHO}$ PFF06, $\mathrm{F}$ medium with $6 \mathrm{mM}$ L-glutamine, and F medium with $5 \%$ CHO PFF06 and $6 \mathrm{mM}$ L-glutamine. The virus titers were detected using flow cytometry to measure GFP+ cells. Data are means (SD) of 3 replicates, ${ }^{* *} \mathrm{P}<0.01$.

\section{Hosted file}

figure 5.pdf available at https://authorea.com/users/374502/articles/492054-establishing293t-suspension-cultrue-for-lentiviral-vector-production-in-a-stirred-bioreactor 
Fig.6

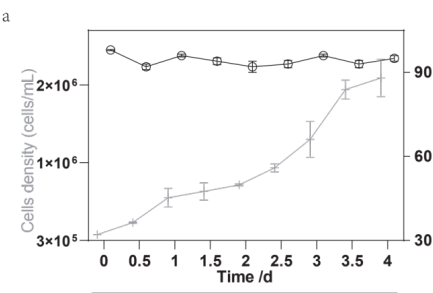

b

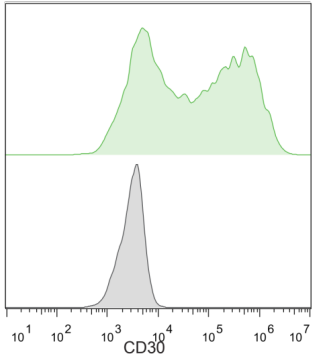

d

Batch 1 Batch 2 Batch 3

$2 \times 10^{7}$
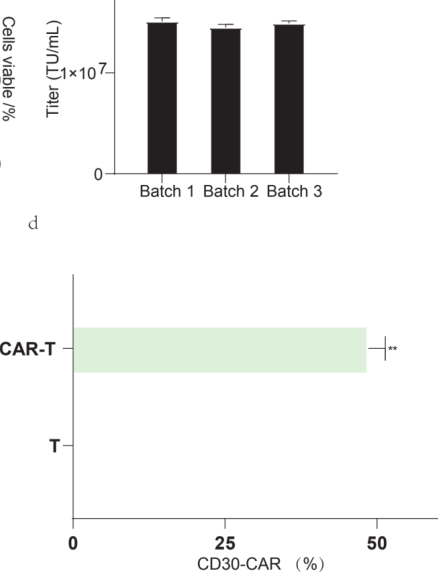

Figure 6. Verification of the virus packaging capability of 293T suspension cells in a $5.5 \mathrm{~L}$ working volume bioreactor. (a) The percentage of cell growth curve and viability during fermentation; (b) Titer of the 293T suspensin cells packing the CAR-CD30 lentivirus. Data are means (SD) of 3 experiments.

(c, d) Inoculated T cells with a MOI of 20 virus were detected using flow cytometer. ${ }^{* *} \mathrm{P}<0.01$.

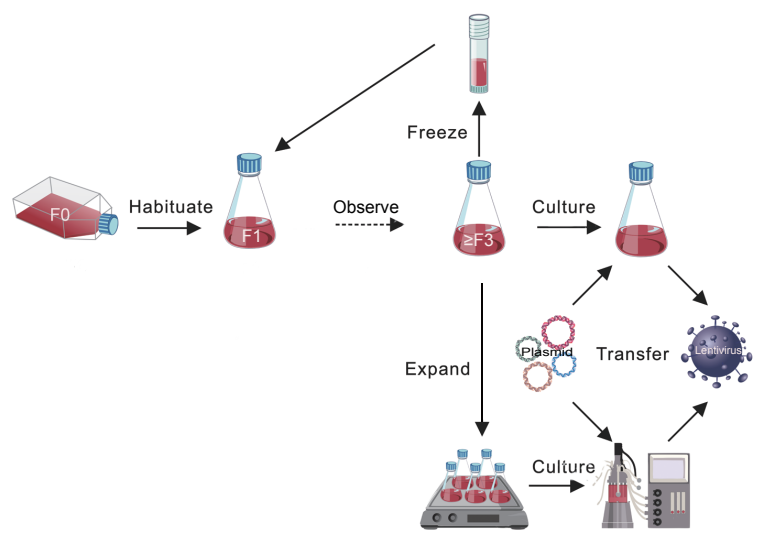

Schematic of the process. Graphical illustration of the 293T suspension culture system for efficient large-scale lentivirus production. ATCC-derived adherent 293T cells were resuscitated and treated as FO adherent cells after stable cultivation for 3 generations. The culture medium of $\mathrm{FO}$ cells was moved from the culture dish to a shaking flask, and the domestication process was completed in 1 week. After 3 passages, the cells could be cryopreserved and subsequently used to produce lentivirus vectors and for large-scale cultivation for lentivirus packaging. Thawing the cells repeats this process. Results of culture,cryopreservation, and transfection experiments revealed the optimized conditions. Additional experiments verified the lentivirus packaging capability in suspension cells. Finally, the resultant optim 